\title{
Examining the relationship between the emotional intelligence and normal people, drug addict, and drug-quitter among no-name addicted groups (NA)
}

\author{
Hamid Kamarzarin*, Maryam Tehranizadeh \\ Department of Psychology, Payame Noor University, PO BOX 19395 - 3697, Tehran, Iran \\ *E-mail address: hkamarzarin2002@yahoo.com
}

\begin{abstract}
Emotional intelligence brings more success in people and makes them treat ordinary problems more wisely. Addiction, which is currently increasing in most societies, causes people to be inoperable as well as causing personal and social devaluation. The present study investigates emotional intelligence in three groups of the members of the society and these include normal people who have never taken any drugs, the drug addicts and drug-quitter in no-name addicted groups (NA). The subjects in the present study are 90 males of Karaj Province in total, which are selected as follows: 30 of them were selected in a simple random sampling method, 30 drug addicts who were selected purposefully and 30 no-name addicted individuals (NA) were selected purposefully. In order to evaluate the emotional intelligence in the present study, Bar-On emotional intelligence questionnaire was used and in order to detect the drug addicts, a self-reporting technique was used. The information used in the present study was obtained from an individual interview. With the aim of analyzing the data, descriptive practices were used to explain the information about the samples and demographic characteristics, as in inferential methods such as variance analysis. The results obtained in the present study showed that the emotional intelligence of the drug-quitters in the (NA) is generally higher than that of the normal and the drug addicts; to be more specific, there is a significant difference between the three groups in all the seven subcategories of the emotional intelligence; that is to say, it was higher in the NA. The seven subcategories contain problem solving, happiness, psychological pressure tolerance, self-actualization, self-esteem, impulse control and self-expression.
\end{abstract}

Keywords: emotional intelligence; NA; drug addict; drug-quitter

\section{INTRODUCTION}

Emotional intelligence includes appropriately processing information which comes with emotional load, so using the information is necessary and essential in order to guide cognitive activities such as solving problems and energy focus into behaviors. The term implies the idea that there are other ways to be intelligent, which are other than emphasizing IQ tests; that is to say, one can raise these abilities as emotional intelligence can be a major 
predicting factor for the success of personal, family and work relationships. Emotional intelligence is appropriate information processing that has an emotional charge and using it is imperative for navigating cognitive activities like problem solution and concentration of energy on conducts. Emotional intelligence represents the ability to ascertain, assess and express emotions properly and adaptively. Also, it includes the ability to understand emotion, awareness of emotions and the ability to attain emotions or to create feelings for facilitating cognitive activities and adaptive conducts and the ability to adjust emotions in the person and in others (Meyer and Salovey, 1997).

\section{The theoretical definition of the emotional intelligence:}

It is the ability, the owner of which can take over his/her emotions through selfawareness and make them better through self-management and perceive its effect through empathy and behave in a manner that can bolster his morale and others' through managing relationships. Nowadays, in academic circles, attachment is used in place of addiction, although common people consider the disorder as addiction" and the patient himself as "addicted". Based on the latest scientific conclusions in 1980s, attachment is a psychological token which make some signs appear in the drug-addict's behavioral, cognitive and psychological moods. The level of attachment is quantitative and can manifest itself to various extents. The degree of the attachment is based on the actions followed by taking drugs. Despite experiencing several problems caused by taking drugs, the patient formed an attachment to drugs is unable to stop taking them and continue doing so under compulsion and obsession. Addiction means getting used to and devoting oneself to a reprehensible habit; in other words, an enslaving affliction with addictive drugs, which are considered to be detrimental to the body and society, is called addiction.

\section{Who is addicted?}

Because of incessantly taking drugs, a drug addict forms a kind of acquired resistance in his body, in the sense that his strength begins to diminish as a result of repeated applications. Thus after a while, he can take more drugs without having any sense of discomfort. If the drug ceases to be arranged for him, certain psychological and physical disorders known as deprivation syndrome will strike at him.

Addiction is a social, psychological and biological disease. Various factors are effective in the etiology of addiction that would in interaction with one another lead to abuse and then addiction. Factors affecting the person, environmental and social factors as background factors will result in the prevention, identification and treatment procedures to be purposefully planned (Islamdust, 2010). Addiction is theoretically defined as a kind of behavior which customarily overwhelms a person to the extent that totally or partially influences person's healthy behaviors. In practice, the term addiction is referred to as continuously and abundantly taking drugs, stimulators, and alcohols. However, it is true once the person feels dependency on them emotionally and physically.

\section{The operational definitions of the words:}

A) Emotional intelligence: the score that a subject can obtain from Bar-On's emotional intelligence questionnaire in the research.

B) Addiction: the score that a subject can obtain from the researcher-made questionnaire on the addiction. 


\section{The statement of the Problem:}

Regarding the capacity of IQ tests (Wechsler, SAT, etc.), what is today discussed in psychology is that no university grades, IO points or the results of causative intelligence tests nor their prestige among people can firmly predict who will get somewhere at last. As for the idea that IQ test can predict achievements, there are some exceptions.

IQ test can at best contribute to the prediction of an achievement in the lifetime as much as $20 \%$, the remaining percent, $80 \%$, is associated with other forces (Goleman, 1995). What force can, according to your idea, the remaining percentage represent? Yes, the major part of it includes emotional intelligence. It involves person's ability to recognize social and emotional self-awareness.

It also constitutes the person's abilities to recognize his own emotions and others' as well as the abilities sufficient for fostering healthy relationships with others and a sense of taking up responsibilities for doing duties. On the contrary, addiction and its adverse effects involve a wide range of physical and psychological side effects, behavioral emotional disorders, family breakdown, divorce and dozens of other instances. The physical damages caused by taking drugs and smoking cigarettes can be passed on to the relatives including wife and children and make them the hidden victims in this story and the second class addicts if they are taken inside the house.

Ultimately, addiction may reduce alertness as increasing vigilance, apathy, depression, anxiety, grief and despair, etc. Therefore, regarding the subject of this study, it is likely that the emotional intelligence bears an inverse relationship with addiction. Thus, the present study, aims to account for the question whether there is generally a relationship between emotional intelligence and addiction, is it inverse or direct?

\section{Significance of the Study:}

A problem can be ironed out during its existence. Emotions can be a means of solving the problems, which are too big to be seen but small enough to be solved. Understanding your emotions, you can skillfully surmount problems and avoid the following ones. If you act otherwise and suppress your emotions, they will be soon turned into tension, and anxiety. Those remain disregarded will disable brain and body. Emotional intelligence abilities allow you to avoid difficult situations before becoming uncontrollable, which make it easier for you to take over stress management (coping with stress).

Moreover, studying history, it is hard enough to find human being who has not struggled with the issues related to addictive drugs, and maybe we can claim that the drugs were born with human in this world and will continue to exist as long as human being live on the earth. The issues pertaining to addictive drugs has not been recently emerged as their effects regularly can be tractable in nations' and different ethnics' destiny. Committing crime on the part of addicts will grow every day because of a weakness in human relationships. As a result of this, public trust in the significance of a society well be endangered, because most addicts are desperate to fall back on wrong action such as robbery, raping others and homicide.

Addiction as a social harm will be never eradicated but it can be manipulated with thought, reflection and devoted endeavor. In this respect, our attempt is to give priority to preventing addiction rather than drug addict treatment through raising the level of awareness of different society classes. It is hoped that we would have a society in which a drug addict is seeking to deliver himself if there is one. Therefore, based on the above information, if the statistical relationship is to be confirmed in this research and if there is a negative mutual 
relationship between emotional intelligence and addiction, so there will be a sense of necessity to take measures in order to improve emotional intelligence and plan for the eradication of addictive drugs and addiction. Generally speaking, the results of the present study can be used to improve emotional intelligence and reduce taking drugs, preventing, treating, and giving up the addiction of the drug addict.

\section{METHODOLOGY}

In order to collect data, the aim of doing research on the study subjects had to be explained in the first place and the information confidentiality of the questionnaire had to be assured and the satisfaction with the subjects was then derived for cooperation. The tests were then performed in an interview manner. In this research, statistical population consists of all the males of Karaj Province. In this research, statistical sample consists of 30 drug addicts, 30 no-name addicts and 30 normal people of Kara Province. The sampling method applied in the present study is in fact a purposeful sampling for selecting the drug addicts and the no-name addicts, so is simple random sampling in the public venues to select the normal people of Karaj Province. These studies include the normal people between the age of 20 and 40, the NA between 27 and 55, the addicted aged 20 to 53 .

Table 1. The average number of people in each group.

\begin{tabular}{|c|c|c|}
\hline Groups & & \\
\hline Normal & 30 & 33.3 \\
Drug & 30 & 33.3 \\
addict & 30 & 33.3 \\
NA & 90 & 100.0 \\
total & 90 \\
\hline
\end{tabular}

Table 2. The mean education levels of the three groups.

\begin{tabular}{|c|c|c|}
\hline Education & Frequency & $\begin{array}{c}\text { Frequency } \\
\text { percentage }\end{array}$ \\
\hline primary & 26 & 28.9 \\
secondary & 19 & 21.1 \\
High school & 7 & 7.8 \\
Diploma & 28 & 31.1 \\
Associated degree & 2 & 2.2 \\
undergraduate & 8 & 8.9 \\
Total & 90 & 100.0 \\
\hline
\end{tabular}




\section{1. Research instruments}

\section{Bar-on emotional intelligence questionnaire:}

In 1980, the Bar-on the emotional intelligence questionnaire was developed for the first time. It contained 133 questions which is the first super cultural questionnaire to evaluate the emotional intelligence. In 1997, this questionnaire had been reviewed and the number of questions expanded to 177. This review was conducted by an author on 3831 persons from 6 different countries and it was performed in the North America. Responses were studied using a factorial analysis and finally a general scale for (IQ), 5 combinational scales and 15 minor scales were determined. In 2003, this test was implemented in Iran among Tehran university students by Dehshiri (2006) and its questions were reduced to 90. In this research, Dehshiri applied the revaluation method and Kronbakh Alphabet. The questionnaire's answer sheets are regulated and based on a scale of 5 degree in Likert spectrum as follows: I agree completely; I agree to some extent, I disagree, I disagree completely). For the final measurement two methods were used. Revaluation sustainability or time stability coefficients were reported respectively as $85 \%$ one month later and $75 \% 4$ month later. Test stability rate in odd-even method was $88 \%$ and $93 \%$ in Kronbakh alphabet (Hasanvand \& Khaledian, 2012).

\section{RESULTS}

In this study, descriptive methods were used for accounting for the information on the samples and demographic features along with inferential statistical methods such as (f) variance analysis. It should be noted that the statistical operation was carried out using SPSS software.

\section{1. Testing hypotheses}

Hypothesis 1) there is a significant difference between the three groups in terms of the score of emotional intelligence.

Table 3. The mean, standard deviation, significance level of the sample.

\begin{tabular}{|l|c|c|c|c|c|}
\hline $\begin{array}{c}\text { Variation } \\
\text { sources }\end{array}$ & $\begin{array}{c}\text { The sum of } \\
\text { squares }\end{array}$ & $\begin{array}{c}\text { Degree } \\
\text { of } \\
\text { freedom }\end{array}$ & $\begin{array}{c}\text { Mean } \\
\text { square }\end{array}$ & F & significance \\
\hline Inter group & 9547.289 & 2 & 4773.644 & 4.737 & .011 \\
Intra group & 87665.833 & 87 & 1007.653 & & \\
\hline total & 97213.122 & 89 & & & \\
\hline
\end{tabular}

As it can be seen, the difference in emotional intelligence is significant at $01 \%$ level. 
Table 4. The hypotheses, 2 to 8 , in the following table and the standard deviation of the three groups according to the emotional intelligence subscales.

\begin{tabular}{|c|c|c|c|}
\hline standardldeviation & mean & & \\
\hline 3.08426 & 20.2667 & normal & \multirow{4}{*}{$\begin{array}{l}\text { Self- } \\
\text { actualization }\end{array}$} \\
\hline 2.44503 & 21.2333 & $\begin{array}{c}\text { Drug } \\
\text { addict }\end{array}$ & \\
\hline 3.23433 & 22.2333 & NA & \\
\hline 3.01797 & 21.2444 & Total & \\
\hline 3.17479 & 17.7000 & normal & \multirow{4}{*}{$\begin{array}{l}\text { Impulse } \\
\text { control }\end{array}$} \\
\hline 3.95739 & 14.8333 & $\begin{array}{c}\text { Drug } \\
\text { addict }\end{array}$ & \\
\hline 6.09965 & 17.0333 & NA & \\
\hline 4.69336 & 16.5222 & Total & \\
\hline 2.18669 & 18.6667 & normal & \multirow{4}{*}{$\begin{array}{c}\text { Self- } \\
\text { expression }\end{array}$} \\
\hline 2.46259 & 16.0667 & $\begin{array}{c}\text { Drug } \\
\text { addict }\end{array}$ & \\
\hline 3.67971 & 19.6667 & NA & \\
\hline 3.20533 & 18.1333 & Total & \\
\hline
\end{tabular}

Table 5. Degree of freedom, standard deviation, and a significant relationship.

\begin{tabular}{|c|c|c|cc|}
\hline $\begin{array}{c}\text { Significant } \\
\text { relationship }\end{array}$ & $\begin{array}{c}\text { Standard } \\
\text { deviation }\end{array}$ & $\begin{array}{c}\text { Degree of } \\
\text { freedom }\end{array}$ & & \\
\hline .001 & 80.578 & 2 & Inter group & $\begin{array}{c}\text { Problem } \\
\text { solving }\end{array}$ \\
\hline & 11.324 & 87 & Inter group & \\
\hline & & 89 & Total & \\
\hline .004 & 83.244 & 2 & Inter group & happiness \\
\hline & 14.107 & 87 & Inter group & \\
\hline .003 & 64.078 & 2 & Inter group & $\begin{array}{c}\text { Psychological } \\
\text { pressure }\end{array}$
\end{tabular}




\begin{tabular}{|c|c|c|c|c|}
\hline & & & \multirow{3}{*}{$\begin{array}{c}\text { Inter group } \\
\text { Total }\end{array}$} & \multirow[t]{3}{*}{ tolerance } \\
\hline & 10.579 & 87 & & \\
\hline & & 89 & & \\
\hline \multirow[t]{3}{*}{.000} & 99.344 & 2 & Inter group & $\begin{array}{c}\text { Self- } \\
\text { actualization }\end{array}$ \\
\hline & 9.007 & 87 & Inter group & \\
\hline & & 89 & Total & \\
\hline \multirow[t]{3}{*}{.040} & 29.011 & 2 & Inter group & Self-esteem \\
\hline & 8.651 & 87 & Inter group & \\
\hline & & 89 & Total & \\
\hline \multirow[t]{3}{*}{.045} & 67.511 & 2 & Inter group & $\begin{array}{l}\text { Impulse } \\
\text { control }\end{array}$ \\
\hline & 20.982 & 87 & Inter group & \\
\hline & & 89 & Total & \\
\hline \multirow[t]{3}{*}{.000} & 103.600 & 2 & Inter group & $\begin{array}{c}\text { Self- } \\
\text { expression }\end{array}$ \\
\hline & 8.129 & 87 & Inter group & \\
\hline & & 89 & Total & \\
\hline
\end{tabular}

Table 6. Standard deviation and the significant relationship between groups.

\begin{tabular}{|c|c|c|c|c|c|}
\hline $\begin{array}{c}\text { Significant } \\
\text { relationship }\end{array}$ & $\begin{array}{c}\text { Standard } \\
\text { deviation }\end{array}$ & mean $(\mathrm{I}-\mathrm{J})$ & $(\mathrm{J})$ groups & $\begin{array}{c}(\mathrm{I}) \\
\text { groups } \mathrm{l}\end{array}$ & $\begin{array}{c}\text { Dependent } \\
\text { Variable }\end{array}$ \\
\hline .246 & .86886 & -1.40000 & Drug addict & normal & Problem solving \\
.001 & .86886 & $-3.26667\left(^{*}\right)$ & $\mathrm{NA}$ & & \\
.246 & .86886 & 1.40000 & normal & $\begin{array}{c}\text { Drug } \\
\text { addict }\end{array}$ & \\
.086 & .86886 & -1.86667 & NA & \\
.001 & .86886 & $3.26667\left(^{*}\right)$ & normal & NA & \\
.086 & .86886 & 1.86667 & Drug addict & & \\
\cline { 4 - 5 } & .56979 & 1.06667 & Drug addict & normal n & Happiness
\end{tabular}




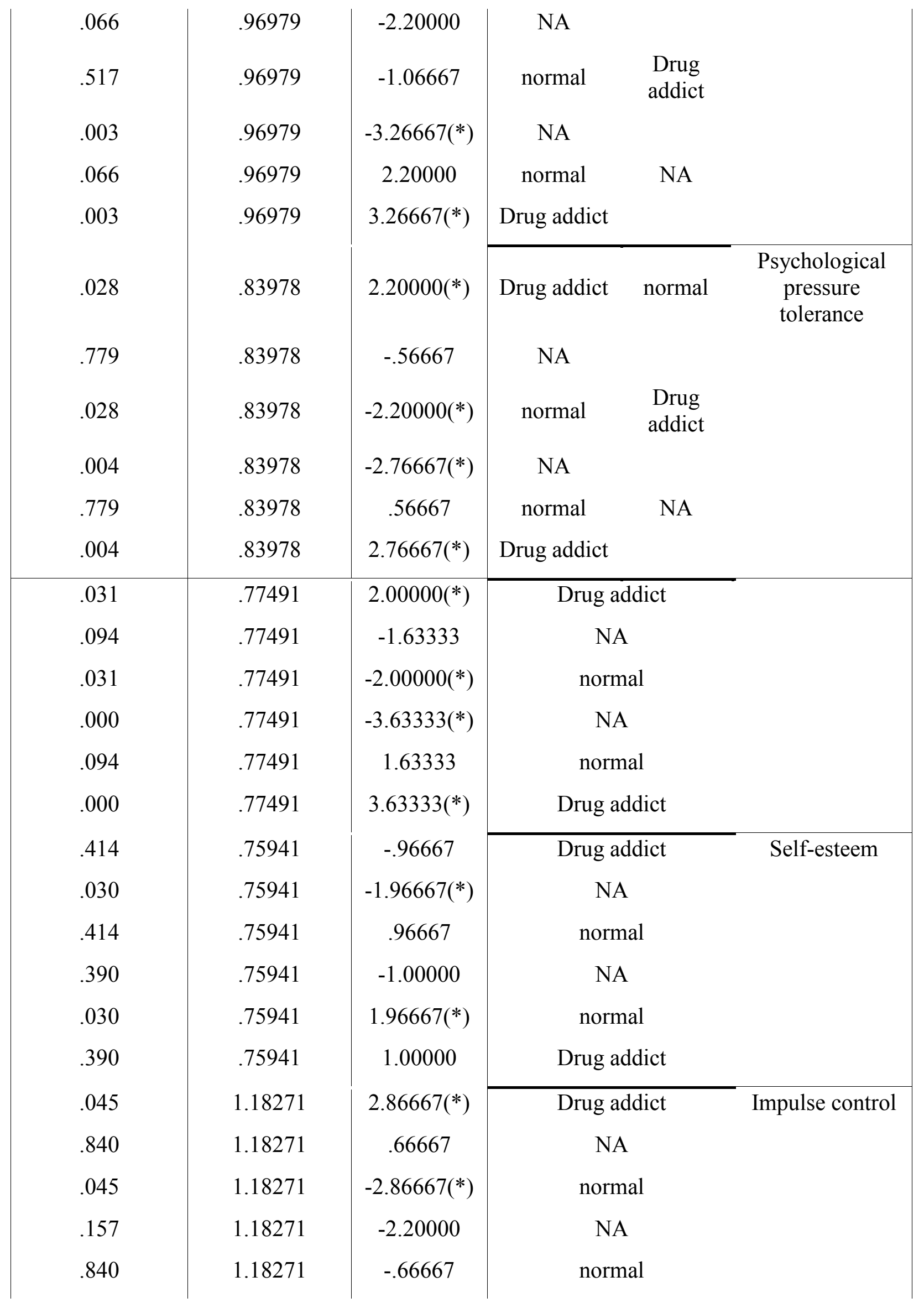




\begin{tabular}{|c|c|c|cc|}
.157 & 1.18271 & 2.20000 & Drug addict & \\
.002 & .73615 & $2.60000(*)$ & Drug addict & Self-expression \\
\cline { 3 - 5 } .367 & .73615 & -1.00000 & NA & \\
.002 & .73615 & $-2.60000(*)$ & normal & \\
.000 & .73615 & $-3.60000(*)$ & NA & \\
.367 & .73615 & 1.00000 & normal & \\
.000 & .73615 & $3.60000(*)$ & Drug addict & \\
\hline
\end{tabular}

In terms of the subscale, problem solving, there is a difference between the NA and normal group, In terms of the subscale, happiness, there is a difference between the NA and normal group, In terms of the subscale, psychological pressure tolerance, there is a difference between the normal group and the drug addict, so is between the drug addict and the NA (the level of psychological pressure tolerance is higher in the NA). In terms of the subscale, selfactualization, there is a difference between the normal group and the drug addict and the NA, (self-actualization is higher in the NA). In terms of the subscale, self-esteem, there is a difference between the normal group and the NA, (the mean of self-actualization of the NA is higher). In terms of the subscale, self-expression, there is a difference among the three groups (the level of the self-expression in the NA group is higher).

\section{DISCUSSION AND CONCLUSIONS}

The present study was aimed to compare the emotional intelligence between the three groups of the society (normal, addicted and NA).

In the first hypothesis, there was a significant difference between emotional intelligence of the three groups of the society. Emotional intelligence of the drug addicts in the NA was higher than the normal and also emotional intelligent of the normal was higher than the drug addict and the difference was due to two reasons:

1) Continuous attendance in the giving-up sessions of the NA: because continuous attendance is one of the rules of quitting drugs in the NA; by attending in the sessions, besides expressing negative and positive feelings that can raise self-confidence, one can tap into other drug-quitters' experiences as well as harnessing veteran professors' remarks in the field of addictive drugs, the goals of which are how to cope with the issues of life, stresses, psychological pressure, as training them how to enjoy life without drugs with enjoyment strategies, the above items are included in the measurements of the emotional intelligence. According to Golman, emotional intelligence can be raised and trained, so that the sessions would increase people's emotional intelligence in a long term.

2) Applying the twelve fold principles of giving up bad habits which are called the twelve steps can be to the benefit of most drug-addicts with their own will after a while by an experienced person's directions. The content of the principles is designed as one can learn how sensible he can deal with problems and stresses and the whole life, so to speak, without any psychological pressure. 
In the second hypothesis, the problem solving subscale, there is a significant relationship between the two groups of the NA and the normal. In the third hypothesis, the happiness subscale, there was a comparison among the three groups, in which the level of happiness was higher than normal as was that of normal higher than the addicted.

The reason, according to the research, is a radical change in the identity and consequently other aspects of his life, so the drug-quitter in the NA would feel relief and happiness which he did formerly by taking drugs, but he can instead achieve it without them. Since one of the principles of the NA is that you should live today, one learn to act wisely with such foresightedness and he can put his trust in God as well as trying to solve them.

If they are deprived of an enjoyment from other aspects of life because of deadliness, they always have a fear and anxiety for a future that has not come yet. A review of the existing findings in the area of emotional intelligence reveals that one of the possible reasons why people are inclined to drug abuse is emotional disability in encountering with stressful events that is a fundamental core of the mental pathology. This has been categorized as defense mechanisms in the psychoanalysis view. In other words, to counter different emotional calls, people make use of special patterns (Spielberg and Reheiser, 2006).

As for the fourth hypothesis, the level of the psychological pressure tolerance between the three groups being compared is higher in the NA than the normal, so is in the normal in proportion to the drug-addicts, which according to the researcher the reason is the educations for the individuals in the NA group sessions as well as the application of the twelve fold principles of behavior changes. Attending the group sessions of the NA as well as taping into the experiences of those who could have attended the sessions, the persons may cope with the problems of the life and raise their level of the psychological pressure tolerance. As for the fifth hypothesis, the self-actualization subscale has been compared among the subjects of the normal, addicted and NA groups, in which it was higher in the NA.

As for the sixth hypothesis, the self-esteem subscale has been compared among the subjects of the normal, addicted and NA groups, in which the mean self-actualization of the NA group was higher. As for the sixth hypothesis, the self-esteem subscale has been compared among the subjects of the normal, addicted and NA groups, in which the mean self-actualization of the NA group was higher. As for the seventh hypothesis, the impulse control subscale has been compared among the subjects of the normal, addicted and NA groups, in which the mean score of the NA was higher. As for the eighth hypothesis, the selfexpression subscale has been compared among the subjects of the normal, addicted and NA groups, in which the level of self-expression in the NA group was higher than others.

\section{The limitations of the Study:}

1) The difficulty with taking emotional intelligence test from the drug addicts regarding the abundance of the questions and the impatience of the drug addicts.

2) The difficulty with taking emotional intelligence test from the drug-quitters in the NA due to the principle of anonymity in the NA group.

3) The inadequacy of advisor professor's attendance hours at university.

4) Lack of recent books appropriate for the present study at university.

\section{Suggestions for Further Studies:}

Students had better study more radically about the present century issue, i.e. addiction, attempting to offer the strategies for quitting it and particularly quitting it more radically in 
the NA group, and they should allow the results to be used by practitioners in the field of addictive drugs.

\section{References}

[1] Hasanvand B., Khaledian M., International Journal of Psychology and Behavioral Sciences 2(6) (2012) 231-236.

[2] Dehshiri Gholamreza, Counseling Researchs And Recents 5(18) (20006) 97-106.

[3] Goleman D. (1995). Emotional intelligence. New York: Bantam Books.

[4] Islamdust S. (2010). Addiction (Etiology, therapy). Tehran: Payam Noor Press.

[5] Mayer J. D., Salovey P. (1997). What is emotion intelligence? In: Salovey P., Sluyter D. J., editors. Emotional development and emotional intelligence: Educational implications. New York: Basic Books.

[6] Spielberger C. D., Reheiser E. C., Personality and Individual Differences 41 (2006) 1033-1043.

[7] Bahram Meihami, Hussein Meihami, International Letters of Social and Humanistic Sciences 3 (2014) 80-91.

[8] Onyike Maggaret Odu, International Letters of Social and Humanistic Sciences 4 (2014) 31-39.

[9] Janusz Grabara, Petre Bosun, International Letters of Social and Humanistic Sciences 14 (2014) 59-65.

[10] Seid Hamed Hosseini, International Letters of Social and Humanistic Sciences 7 (2014) $67-75$.

[11] Nadeem Iqbal, Naveed Ahmad, Zeeshan Riaz, International Letters of Social and Humanistic Sciences 9 (2014) 14-25.

[12] Sakineh Ghayazi, Faranak Omidian, Mohammed Hosseinpoor, International Letters of Social and Humanistic Sciences 10(1) (2014) 51-61.

[13] Morteza Ziaee, International Letters of Social and Humanistic Sciences 10(2) (2014) 172-180.

[14] Gholamreza Jandaghi, Hamid Reza Irani, Ehssan Jandaghi, Zeinab Sadat Mousavi, Maryam Davoodavabi, International Letters of Social and Humanistic Sciences 15(1) (2014) 7-13.

[15] Gholamreza Jandaghi, Hamid Reza Irani, Ehssan Jandaghi, Zeinab Sadat Mousavi, Maryam Davoodavabi, International Letters of Social and Humanistic Sciences 15(1) (2014) 78-83.

[16] Heman Mahmoudfakhe, Morad Abdivarmazan, Toba Amini, International Letters of Social and Humanistic Sciences 15(2) (2014) 84-91.

[17] Sule Maina, International Letters of Social and Humanistic Sciences 4 (2014) 87-96.

[18] Hussein Meihami, Bahram Meihami, International Letters of Social and Humanistic Sciences 5 (2014) 63-72. 
[19] Mohamad Khaledian, Galavizh Khaledian, Jabar Sadeghi, Reza Keyhanihekmat, International Letters of Social and Humanistic Sciences 6 (2013) 62-67.

[20] Mohamad Khaledian, Zahra Ahmadimehr, Elham Naseri, Fakhralsadat Khosravani, Mojgan Shoshtsri, International Letters of Social and Humanistic Sciences 8 (2013) 43-48. 